\title{
Retraction: Guggulsterone inhibits prostate cancer growth via inactivation of Akt regulated by ATP citrate lyase signaling
}

\section{Yajuan Gao, Yan Zeng, Jian Tian, Mohammad Shyful Islam, Guoqin Jiang and Dong Xiao}

Published in Oncotarget, Advance publications. This article has been retracted due to falsified data in Figures 1,4,5,S2 and $\mathrm{S} 3$ reporting tumor experiments on animals.

The authors sincerely apologize to the scientific community for any confusion or adverse consequences resulting from the publication of this data.

http://www.impactjournals.com/oncotarget/index.php?journal=oncotarget\&page=article\&op=view\&path[]=2138\&au thor-preview $=1$ ne 